\title{
Reflective journals: unmasking student perceptions of anatomical education
}

\author{
L. Lazarus ${ }^{1}$, R. Sookrajh ${ }^{2}$, K.S. Satyapal ${ }^{1}$ \\ ${ }^{1}$ Department of Clinical Anatomy, School of Laboratory Medicine and Medical Sciences, College of Health Sciences, \\ University of KwaZulu-Natal, Westville Campus, Durban, South Africa \\ 2Department of Curriculum Studies, School of Education, College of Humanities, University of KwaZulu-Natal, \\ Edgewood Campus, Pinetown, South Africa
}

[Received: 29 August 2016; Accepted: 18 November 2016]

Background: In medical education, reflection has been considered to be a core skill in professional competence. The anatomy laboratory is an ideal setting for faculty/ student interaction and provides invaluable opportunities for active learning and reflection on anatomical knowledge.

Materials and methods: This study was designed to record student attitudes regarding human cadaveric dissection, explore their experiences of anatomy through an analysis of their journal-reflective writings and determine whether this type of creative writing had a beneficial effect on those students who chose to complete them. A total of 75 journals from Medical and Allied Health Science students were collected and analysed. Results: Results were categorised according to the following themes: (i) Dissecting room stressors (27.6\%); (ii) Educational value of dissection (26.3\%); (iii) Appreciation, Gratitude, Respect and Curiosity for the cadaver (18.9\%); (iv) Positive and negative sentiments expressed in the dissecting room (25.8\%); (v) Benefit of alternate teaching modalities (4.6\%); (vi) Spirituality/Religious Beliefs (3.7\%); (vii) Shared humanity and emotional bonds (3.69\%); (viii) Acknowledgement of human anatomical variations (3.2\%); (ix) Beauty and complexity of the human body (1.8\%) and (x) Psychological detachment (0.9\%). Students appreciated the opportunity to share their emotions and reflect on the humanistic dimension of anatomy as a subject. Student reflections illustrated clearly their thoughts and some of the difficult issues with which they wrestled. Conclusions: The anatomy laboratory is seen as the budding clinician's first encounter with a patient, albeit a cadaver. This was the first time that reflective journals were given to students in the discipline. Reflective journals allow students to express themselves in an open-ended and creative fashion. It also assists students to integrate anatomy and clinical medicine and assists in applying their basic anatomical knowledge in an authentic, yet safe environment. (Folia Morphol 2017; 76, 3, 506-518)

Key words: reflection, journal writing, anatomy, medical education, cadaveric dissection

\section{INTRODUCTION}

Reflection, as defined by John Dewey, is a "purposeful form of thought provoked by unease in learners when they recognise that their understanding is incomplete"
[28]. It is also regarded as a process regarding thinking about and exploring an issue of concern which is triggered by an experience [11]. Specifically, in medical education, reflection has been considered to be a core

Address for correspondence: Prof. K.S. Satyapal, Department of Clinical Anatomy, School of Laboratory Medicine and Medical Sciences, College of Health Sciences, University of KwaZulu-Natal, Private Bag X54001, Durban, 4000, South Africa, tel: +27 $312607110,+27837778780$, fax: +27 31260 7890, e-mail: satyapalk@ukzn.ac.za 
skill in professional competence [47]. Journal writing has been considered as a means to facilitate reflection and allow students to express feelings regarding their educational experiences.

According to the literature reviewed, reflective learning has become increasingly popular within the domain of medical education [81] and other health related professions such as nursing $[4,63]$. Reflection using journal writing has been described and explained in many different ways [87] and has been utilised in a variety of professions such as nursing $[24,36,72,95]$, physical therapy [91, 92]; occupational therapy [85] and teacher certification $[13,17]$.

The anatomy laboratory is an ideal setting for faculty/ student interaction and provides invaluable opportunities for active learning and reflection on anatomical knowledge. Despite reductions in its importance, time allocation and status within the domain of anatomical education in modern curricula, anatomical knowledge remains the bedrock in medicine and related health professions [2] . Human dissection within gross anatomy courses usually occurs early in undergraduate medical and allied health science curricula [16]. There have been many studies conducted worldwide on the role of dissection and its effect on the encouragement of humanistic qualities of respect, empathy and compassion, all of which embrace the concepts of socialisation and professionalisation in medical education $[22,31,32,65,67,73,84]$. Hafferty [31] further stated that the experience of dissection is regarded as an emotional rite of passage which promotes the process of changing over from layperson to doctor. Bertman and Marks [7] reported that this ritual takes place via a psychological process of which very little is yet known. According to Woodward [96], reflective journal writing allows students to ask questions, reflect on their own learning processes and make a connection between their theoretical understanding and personal experience in practice.

Dissection offers students opportunities to recognise and come to the realisation that the cadaveric donors that they are exposed to, were once living people with a name, family and life history. There is a dichotomy of opinion in the literature with regard to the role played by the cadaveric donor. Newell [58] labelled dissection as the "royal road" with the cadaver that students explore, in essence, being the "first patient" [15, 91]. Prakash et al. [70] stated that when dissecting a cadaver, the student is faced with the reality of life - morbidity and mortality - as well as the remarkable responsibility of a clinician to care for a patient. Other authors such as Winkelmann and
Güldner [94] and Bohl et al. [9] reported that students see the cadaver as a great teacher, thus attributing a social role and status to it. The student-cadaver encounter in medical education is regarded as a "nodal point" [68] a moment in time which can result in compassionate detachment on the part of the student that is essential if the future clinician is to cope with issues such as death and bereavement [23] and causes them to reflect on issues of human dignity and grief [34]. Despite this detachment, students are encouraged to develop personal relationships with their cadavers based on the same gratitude and respect that is afforded to highly regarded teachers [9]. Regrettably, students may be inadequately prepared for their initial encounter with the human body and they may experience a variety of emotions [16]. The literature is replete with studies documenting dissection room experiences [76]. Many studies report on the negative emotions such as anxiety, disgust and/or apprehension experienced by students $[18,19,30,35,60,78,79$, 88]. According to Shapiro et al. [78], this anxiety is both natural and healthy, especially if it leads to reflection and self-analysis. O'Carroll et al. [60] reported that stress is heightened by intensive psychological and physical reactions with some students experiencing sleep disorders. Nnodim [59] reported students experiencing intensive anxiety which can reach the level of post-traumatic stress [25]. Physical reaction to cadavers include revulsion at the sight and smell of it, shock at confronting death, desecration and dismemberment, violation of cultural taboos, dehumanisation and invasion of privacy [2]. On the other hand, some students express positive emotions towards the process of dissection [49] such as interest, excitement and the need for acquiring new knowledge $[12,54]$.

Further to learning to cope with the exceedingly "emotional confrontation" with the cadaver [70], additional outcomes identified in the dissecting room experience include teamwork, respect and familiarisation for the body, application of practical skills, integration of theory and practice, preparation for clinical work and an appreciation of the status of dissection within the history of medicine [49].

The attitudes and beliefs of South African medical and allied health science students regarding cadaveric dissection experiences have not been thoroughly explored. Kotze et al. [44] reported student fears of dissecting the face, possible collapse or vomiting and feelings of sadness in a study conducted at Stellenbosch University in South Africa. South Africa is a multi-cultured society having sacred rituals with regard to handling the dead [77]. Sobnach et al. [80] reported an incidence of $17 \%$ of 
medical students at the University of Cape Town (South Africa) who believed in an after-life with a view that the body must be kept intact after death. This importance of having an intact body is stressed in certain religious groups and is associated with respect for the ancestors and the idea of an after-life [46, 48]. Kometsi and Louw [43] further explored the concept of ancestors which is defined as "a belief, that after death, one joins a spiritual world that works in collaboration with and in immediate subordination to God over humankind". Satyapal [77] reiterated that their 'spirits' (amadlozi) should also be at peace. Ndlovu [57] stated that ancestors are thought to communicate personal messages or messages from God to living human beings through symbols like dreams.

Another crucial concept highlighted as part of the dissection experience is the presence of human anatomical variations. Older [61] maintains that students may come across these variations as some of them may be common and are often of clinical importance. Bernard [6] cited additional benefits of cadaveric dissection such as an enhanced understanding of course material and the provision of a "true picture of the human structure".

The Department of Clinical Anatomy at the University of KwaZulu-Natal is comprised of two teaching delivery sites, viz. the Nelson R. Mandela School of Medicine and the Westville Campus. On both delivery sites, preparation before practical sessions usually follows a schedule and seldom touches on how to manage emotions. There is only an introductory lecture on the rules and regulations to be followed in the dissecting room but no organised discussion or reflection on dissection experiences. In addition, a Dedication Ceremony is only conducted at the Nelson R. Mandela School of Medicine campus. In many of the studies alluded to above, experiences were examined retrospectively by recollection using structured questionnaires. There have been no studies at South African Anatomy Departments that recorded student attitudes as they progressed through a dissection roombased anatomy curriculum using reflective-journaling. In this respect, our study was unique. Therefore, this investigation was designed to record student attitudes to human cadaveric dissection, explore their experiences of anatomy through an analysis of their journal-reflective writings and determine whether this type of creative writing had a beneficial effect on those students who chose to complete them.

\section{MATERIALS AND METHODS}

The study sought to explore medical and allied health student experiences of anatomical teaching and learning at the Department of Clinical Anatomy, University of KwaZulu-Natal, Durban, South Africa. A total of 298 journals were distributed to all second year MBChB $(n=197)$ and Allied Health students comprising second year Bachelor of Physiotherapy $(n=40)$ and Medical Science $(n=27)$ students as well as first year Occupational Therapy $(n=34)$ students. At the time of the study, anatomy practical teaching sessions were comprised of full body gross anatomy dissections in the first semester of the academic calendar. All students attended two three-hour anatomy classes per week. The content of the practical sessions were pre-determined by Faculty within the Department of Clinical Anatomy at the beginning of the academic semester. All anatomy practical sessions took place in the traditional setting of the dissecting laboratory where students had full access to resources including whole body cadaveric prosections and skeletons. Students were also given access to three-dimensional plastic models and anatomy videos to supplement cadaveric dissection in this setting (plastic torsos with muscles and ligaments, including heart and lung models). Teaching methods utilised in the dissection laboratory included small group teaching with up to 11 students per cadaver. Demonstrator-led classes (overseen by lecturers) were conducted by postgraduate students having majors in Anatomy.

The primary outcome measure of this study was student opinion of dissection-laboratory experiences related to the teaching and learning of anatomy. With the approval of the University of KwaZulu-Natal's Ethics Committee (BE386/15), all of the above students were invited to partake in the study by giving their written consent. Students were not compelled to provide demographic data in this study. Completion of the journal was purely on a voluntary basis with no compulsion on the student and was not a component of the assessment criteria of the course. With this design in mind, we chose to focus on the completed journals and evaluated student perceptions of their dissection room experiences without any extrinsic effects from assessment or course requirements.

The first (LL) and second (RS) authors summarised all narrative interpretations which were coded using a grounded theory approach [83]. Thematic content analysis was employed to identify recurring words and categories which emerged from the data and these were subsequently organised into themes. The various themes were reviewed and discussed until the authors identified an overarching theme that they felt represented the large majority of journals reviewed. The data was analysed by frequencies and percentages of the themes using QSR NVivo 10 software package. 


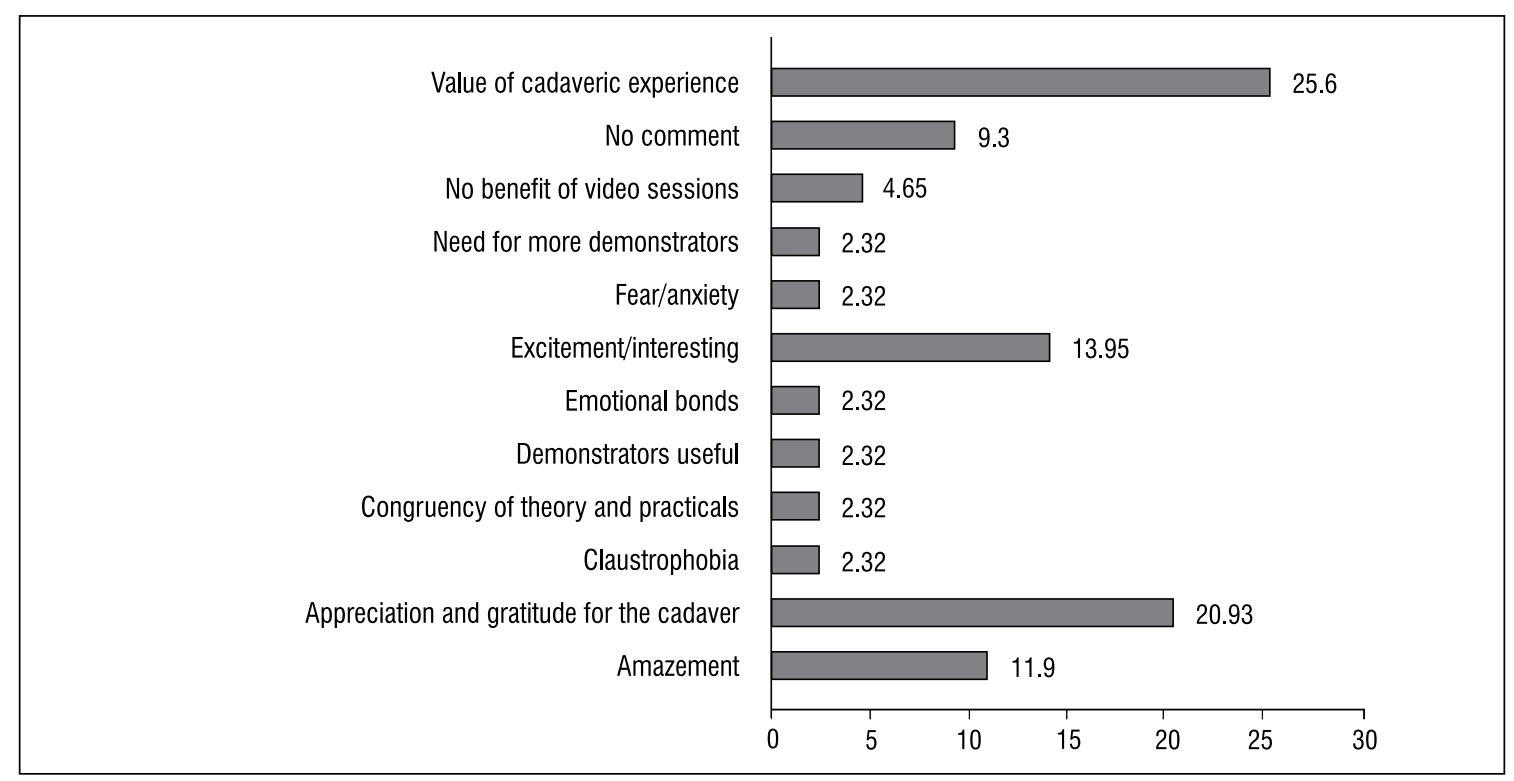

Figure 1. Summary of coding categories for MBCHB students $(n=10)$.

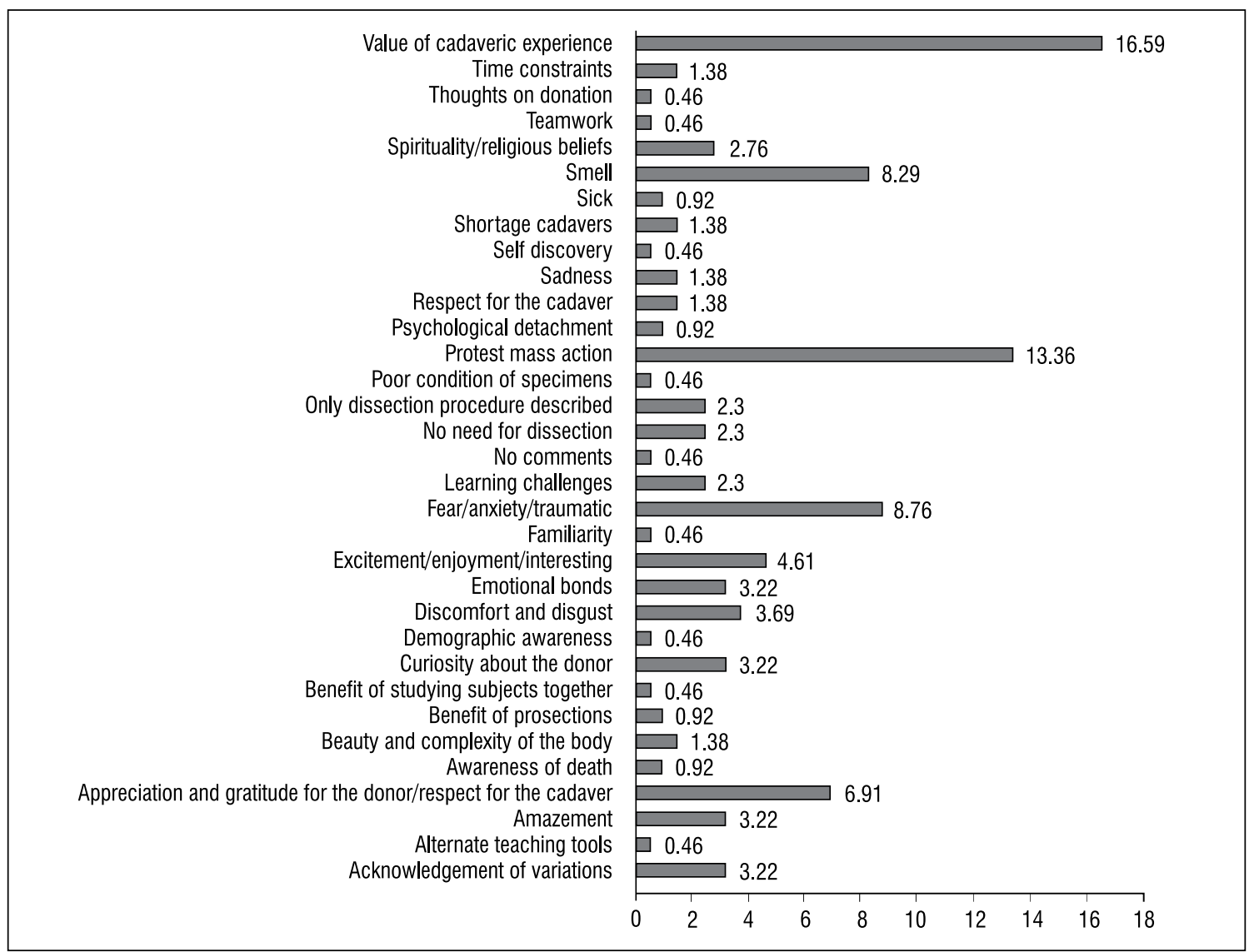

Figure 2. Summary of coding categories for allied health science students $(n=65)$.

\section{RESULTS}

A total of 75 journals were collected from students and analysed. The format varied widely from some highly reflective accounts of the writer's feelings to factual records of students' experiences in the dissecting room.
A total of 217 responses were extracted from the journals. Figures 1 and 2 illustrate the coding categories of responses obtained from medical and allied health science students, respectively. From these, a total of 9 themes emerged (Table 1) from the data. In order to adequately 
Table 1. Thematic areas identified

\begin{tabular}{lc}
\hline Thematic area & Incidence (\%) \\
\hline I. Dissecting room stressors & $60(27.6 \%)$ \\
II. Educational value of dissection & $57(26.3 \%)$ \\
III. Appreciation, gratitude, respect and & $41(18.9 \%)$ \\
$\quad$ curiosity for the cadaver & \\
IV. Sentiments expressed in dissecting room: & \\
$\quad$ Positive emotion & $29(13.4 \%)$ \\
$\quad$ Negative emotion & $27(12.4 \%)$ \\
V. Organised learning and camaraderie & $10(4.6 \%)$ \\
VI. Spirituality/religious beliefs & $8(3.7 \%)$ \\
VII. Shared humanity and emotional bonds & $8(3.7 \%)$ \\
VIII. Acknowledgment of human anatomical & $7(3.2 \%)$ \\
$\quad$ variations & \\
IX. Beauty and complexity of the human body & $4(1.8 \%)$ \\
X. Psychological detachment & $2(0.9 \%)$ \\
\hline
\end{tabular}

explain each of these themes, direct quotations have been extracted from the journals as follows.

\section{THEME I: DISSECTING ROOM STRESSORS (27.6\%)}

The majority of respondents cited protest mass action as a cause of limited time in the dissecting room.

"Dissecting the lower limbs felt quite rushed since we had many disruptions due to the strikes."

The smell of the dissecting room caused physical discomfort with some students

"Our cadaver is very potent and after 2 hours the smell is unbearable, the chemicals are making your nose run and your eyes burn and everyone is unhappy."

"The size of the groups I feel are way too large. For example when it came to removing the heart every single group member insisted on cutting one vessel. This kinda ruined the learning experience as everyone was pushing each other out of the way in order to get to the cadaver. Therefore, no one really got to see what was going on."

\section{Learning challenges}

"We did the anterior and posterior compartment [of the lower limb]. I found this to be challenging because there are various new names of muscles we need to know. Also trying to understand the function of each muscle is difficult as we are trying to understand the movement of the muscle, origin and insertion without actually seeing the cadaver move."
Shortage of cadaveric material and poor quality of specimens

"I didn't like the condition that some of the specimens were in. They were tattered and this made it difficult for me to identify the structure as a whole."

\section{THEME II: EDUCATIONAL VALUE OF DISSECTION (26.3\%)}

A total of $26.3 \%$ of journal responses referred to the cadaver as a useful tool for learning. The cadavers were depicted and viewed as a source of knowledge that ultimately helps others.

"It was nice to see the muscles in real life, and not only in a book."

"I felt working on the cadavers and dissecting was very helpful with understanding the body as a whole."

"Learning theoretically is just knowing what everything is but seeing, touching and identifying with variation is making a person understand the function relating to structure and how the structure is a certain way to perform a specific function."

\section{THEME III: APPRECIATION, GRATITUDE, RESPECT AND CURIOSITY FOR THE CADAVER (18.9\%)}

Students' dominant positive emotion toward the cadaver was one of appreciation and gratitude. The responses expressed specific gratitude for the cadaver's role in contributing to the graduating of future "doctors and health practitioners."

"I think those who have donated have done a noble act and deserve honour and praise because they did something right which will not only improve the knowledge of students but it also prepares future doctors and other health practitioners."

Students were portrayed as respectful and compassionate people who were curious about the lives of the donors and who tried to get emotionally close to the cadaver. There was a feeling of wanting to further protect the cadaver from any harm.

"... couldn't help but realize that this person had once had a life, filled with happiness and joy as well as pain and sadness."

"I believe that those that donate their bodies to medical research are the real heroes here. If it wasn't for them, then medicine wouldn't be where it is today. We need these selfless individuals and their families. Our responsibility as researchers is to respect their bodies by not doing anything insulting regardless of the fact that the human soul is no longer within them." 


\section{THEME IV: SENTIMENTS EXPRESSED IN THE DISSECTING ROOM (25.8\%)}

Positive emotion towards cadaver (13.4\%)

The cadaver often evoked positive feelings of amazement, excitement and interest in students. Dissection became the vehicle that allowed the discovery of this marvel.

"Dissecting was an amazing experience of a lifetime although it can be frightening and exciting at the same time."

"It is exciting to open the human body, it inspires and improves knowledge."

Negative emotion towards cadaver (12.4\%)

Dissection also appeared to arouse negative feelings of fear and anxiety, sometimes even revulsion and disgust, in some students.

"It was quite a shock seeing our cadaver for the first time. It was a very scary thing. I have never seen a dead person before, and found it very emotional to be by one. I was okay with the cadavers wrapped up, but seeing the flesh made me nauseous and emotional."

"...the sight of the cadaver makes me sick, the smell is even making things worse."

\section{THEME V: ORGANISED LEARNING AND CAMARADERIE (4.6\%)}

Students mentioned aspects such as the advantages of prosected specimens, assistance from table demonstrators in the laboratory, benefits of learning theoretical information together with the practicals enhancing the learning experience and the importance of team work.

"It's always fun dissecting at the $\mathrm{DH}$ with my fellow classmates as we are able to prioritize and also make time for a little laughter. We always work as a team and this enables us to also learn faster."

"It was useful to have a lecture on the same subject matter in the morning before $\mathrm{DH}$. "

\section{THEME VI: SPIRITUALITY/RELIGIOUS BELIEFS (3.7\%)}

In a student body characterized by religious diversity, some students made reference to their religious and cultural beliefs. These students thought about the souls of the deceased. However, the overall impression was that there seemed to be no contradiction or conflict between their faith and their science and they understood the benefit of the cadaver.

"I was scared at first when I saw the cadavers covered in the plastic bag like I used to see it in the movies.
I couldn't believe that those were dead people and I was going to touch and see. But there was a little excitement to see the body and dissect and see all these structures we learn in theory. But when I reported at home that I am doing this, it caused a big argument between me and father as he believes in ancestors. He told me that I am disturbing the peaceful soul as the person I am dissecting, he or she will come into my dreams. I also believe in ancestors so this made me thinking a lot about the excitement of seeing the internal organs and vessels."

"In my culture, it is pretty taboo to donate your body to science as it is believed that once you die, you are supposed to be buried with your forefathers and with all your organs intact and present. If your organs are missing, the elders believe that your soul won't be recognized by your ancestors and in effect your soul will never find peace and will roam freely and cause disruptions because it is restless and searching for their own."

\section{THEME VII: SHARED HUMANITY AND EMOTIONAL BONDS (3.69\%)}

Connection was also expressed through recognizing the shared humanity of cadaver and student. Some students commented on the presence of nail polish on the cadaver's fingers. Such evidence of the cadaver's personhood triggered imagery about the life of the cadaver.

"Our first experience in the dissection hall was really emotional. I had mixed emotions as I was partially excited to see a real human body's anatomy first hand, but I was also sad when I saw the cadaver for the first time. I was able to man up and swallow my fears but when I saw our cadaver's hands, she had pink cutex and that humanized me more which brought on the waterworks."

Some students created an emotional bond with their cadaver by naming it and reflected on how access to this material had affected them personally.

"Chandler Bing is what I named our cadaver. Reason for his unique name: To give him a bubbly personality, as I imagined him to have had when he was alive."

\section{THEME VIII: ACKNOWLEDGEMENT OF HUMAN ANATOMICAL VARIATIONS (3.2\%)}

Students also acknowledged the presence of anatomical variations.

"Discovered interesting variation of the left brachial artery. Trifurcated as opposed to bifurcated. Also does so in the arm as opposed to the cubital fossa. Such a discovery would not be possible without the use of cadavers." 
Table 2. Positive sentiments expressed by students towards the cadaver

\begin{tabular}{llcc}
\hline & Author (year) & Sample size (n) & Incidence (\%) \\
\hline Eager and excited & McGarvey et al. (2001) [52] & 188 & 95 \\
& Cahill and Ettarh (2009) [12] & 166 & 19.2 \\
& Mulu and Tebagu (2012) [55] & 147 & 53.7 \\
& Oyeyipo and Falana (2012) [62] & 60 & 70 \\
& Karau et al. (2014) [42] & 75 & 85.3 \\
& Kumar (2015) [45] & 150 & 60 \\
& Purvi et al. (2015) [71] & 150 & 70.6 \\
Enjoyable/fascinating/interesting & Cahill and Ettarh (2009) [12] & 166 & 48.4 \\
& Dubhashi et al. (2011) [20] & 415 & 80 \\
Surprise & Mulu and Tebagu (2012) [55] & 147 & 91.8 \\
Helpful & Kumar (2015) [45] & 150 & 40 \\
Sense of gratitude to people who donated their bodies & Dubhashi et al. (2011) [20] & 150 & 17.3 \\
\hline Overall weighted mean & Purvi et al. (2015) [71] & 415 & 67 \\
\hline
\end{tabular}

\section{THEME IX: BEAUTY AND COMPLEXITY OF THE HUMAN BODY (1.8\%)}

Students were able to appreciate the complexity of the human body.

"Seeing the detail of the organs without the business of dissection and fear of the cadavers was fantastic as we could focus better on studying carefully the detail and appreciating our bodies' make-up"

\section{THEME X: PSYCHOLOGICAL DETACHMENT (0.9\%)}

Some students felt that they had to separate themselves from the cadaver in order for them to get on with the job.

"I felt I had to separate myself from the cadaver and not think too much about the 'person' it once was but think of it as a 'body'."

\section{DISCUSSION}

The results of this study, following thematic analyses, illustrated that student participation in the journaling process promoted self-reflection about anatomy and health care, examined the student-cadaver relationship, probed questions about spirituality and religion and explored the emotional responses to dissection. Our study compares favourably with that reported by Shapiro et al. [78], who cited that students actively engage in reflecting on the meaning and significance of anatomy - with some students having a tendency to emotionally over - identify with cadavers, whilst others were more likely to imagine them humanistically.
Students were able to articulate awe and wonder at the intricacies of the human body and express appreciation for the gift of the donor. In this study, students were able to appreciate the value of dissection concurring with numerous studies in the literature that advocate the use of dissection as a teaching tool [3, 12, 39, 40, 53, 97].

Stressors associated with dissection have been welldocumented and available literature suggests that the majority of students studying anatomy adapt well to these stressors for the duration of their course $[14,25$, 66, 75].

The present study, following an extensive literature survey, illustrates that students experience an array of positive (Table 2 ) and negative (Table 3 ) sentiments towards dissection. A calculated overall weighted mean of the positive sentiments (55\%) compared favourably to the sentiment of eagerness and excitement as reported by Mulu and Tebagu [55] (Table 2). Students' positive attitudes towards dissecting human cadavers could be related to a representation of the body, life and death leading to a future professional assuming a more humane relationship with his/her future patients [29]. In this study, an overall weighted mean of $37.4 \%$ obtained for negative emotions towards cadaveric dissection concurred with feelings of fear and anxiety as expressed by Oyeyipo and Falana [62], as well as that of hesitancy to dissect the cadaver as reported by lzunya et al. [37] (Table 3).

An overall calculated weighted mean of $15.2 \%$ for a diverse range of physical effects experienced by students in the dissecting laboratory was similar to that reported by various authors in the literature, viz. loss of appetite [45], dizziness [64], palpitations [27] and restlessness 
Table 3. Negative sentiments expressed by students towards cadaver

\begin{tabular}{|c|c|c|c|}
\hline & Author (year) & Sample size (n) & Incidence (\%) \\
\hline \multirow[t]{13}{*}{ Fear/anxiety } & Javadnia et al. (2006) [38] & 68 & 32 \\
\hline & Dubhashi et al. (2011) [20] & 415 & 61 \\
\hline & Gualdrón et al. (2011) [29] & 904 & 23.3 \\
\hline & Naz et al. (2011) [56] & 500 & 16 \\
\hline & Bernard (2012) [6] & 212 & 60 \\
\hline & Mulu and Tebago (2012) [55] & 147 & 12.2 \\
\hline & Oyeyipo and Falana (2012) [62] & 60 & 36.7 \\
\hline & Patel et al. (2012) [64] & 150 & 24 \\
\hline & Agnihotri and Sagoo (2010) [2] & 300 & 86.7 \\
\hline & Bob et al. (2015) [8] & 138 & 40.6 \\
\hline & Kumar (2015) [45] & 150 & 61.3 \\
\hline & Saha et al. (2015) [74] & 99 & 3 \\
\hline & Somanath et al. (2015) [82] & 141 & 14 (M); 17 (F) \\
\hline \multirow[t]{4}{*}{ Emotional shock } & Izunya et al. (2010) [37] & 104 & 53 \\
\hline & Karau et al. (2014) [42] & 75 & 30.7 \\
\hline & Somanath et al. (2015) [82] & 141 & $24(\mathrm{M}) ; 35$ (F) \\
\hline & Naz et al. (2011) [56] & 500 & 16.2 \\
\hline Stress & McGarvey et al. (2001) [52] & 188 & 2 \\
\hline \multirow[t]{4}{*}{ Hesitancy to dissect the cadaver } & Izunya et al. (2010) [37] & 104 & 35 \\
\hline & Dubhashi et al. (2011) [20] & 415 & 40 \\
\hline & Saha et al. (2015) [74] & 99 & 24.2 \\
\hline & Somanath et al. (2015) [82] & 141 & 41 (M); 50 (F) \\
\hline Depression & Kumar (2015) [45] & 150 & 14.7 \\
\hline Horror & Purvi et al. (2015) [71] & 150 & 12 \\
\hline \multirow[t]{3}{*}{ Sense of feeling sad } & Evans and Fitzgibbon (1992) [23] & 167 & 41 \\
\hline & Oyeyipo and Falana (2012) [62] & 60 & 46.7 \\
\hline & Patel et al. (2012) [64] & 150 & 21.3 \\
\hline Overall weighted mean & & \multicolumn{2}{|c|}{37.4} \\
\hline
\end{tabular}

$[2,38]$ (Table 4). Table 5 outlines a number of physical and psychological factors emanating from student-cadaveric interaction. Many students complained of the "smell" of the dissecting laboratory (Bataineh et al. [5] (58.5\%), Mulu and Tebago [55] (52.4\%) and thoughts about the donor [64]; these studies are akin to the calculated overall weighted mean of $55.8 \%$ culled from the literature.

In this study, students took it upon themselves to name the cadaver, thereby connecting emotionally with the donor (3.7\%). This concurs with that reported by Williams et al. [93], who stated that the practice of naming cadavers is an extremely prevalent occurrence among medical students and that this sort of inventive naming serves as a beneficial coping mechanism. Naming "allows students to acknowledge the cadaver's personhood, while psychologically shielding themselves enough to be comfortable with the dissection" [93]. Our study also highlighted an urgent need to know, in the form of curiosity, details regarding the life of the donor (18.9\%), concurring with that reported by Fitzgerald [26].

Our students come from various socio-economic backgrounds and belong to a wide range of religious and cultural groups [10]. In this investigation, students commented on issues of spirituality and cultural beliefs as stressors to dissection. Sobnach et al. [80] highlighted the importance of an intact body in certain religious groups. This belief is associated with respect for the ancestors and the idea of an after-life $[46,48]$. We made similar observations in our study, where students who believed in an after-life (the concept of 'amadlozi') (3.7\%) were significantly affected by cadaveric dissection.

The interpretation of student journal writing suggests a variety of expressions experienced by students. Inviting students to reflect is asking students to share their deepest thoughts [21]. Students appreciated the opportunity to share their emotions and reflect on the 
Table 4. Physical effects experienced by students in the dissecting room

\begin{tabular}{|c|c|c|c|}
\hline & Author (year) & Sample size (n) & Incidence (\%) \\
\hline \multirow[t]{4}{*}{ Fainting } & Mulu and Tebagu (2012) [55] & 147 & 2 \\
\hline & Patel et al. (2012) [64] & 150 & 2 \\
\hline & Getachew (2014) [27] & 206 & 3.4 \\
\hline & Purvi et al. (2015) [71] & 150 & 1.3 \\
\hline \multirow[t]{4}{*}{ Loss of appetite } & Abu-Hijleh et al. (1997) [1] & 205 & 22.5 \\
\hline & Patel et al. (2012) [64] & 150 & 2.7 \\
\hline & Getachew (2014) [27] & 206 & 38.8 \\
\hline & Kumar (2015) [45] & 150 & 12 \\
\hline \multirow[t]{5}{*}{ Diziness } & Javadnia et al. (2006) [38] & 68 & 2.9 \\
\hline & Agnihotri and Sagoo (2010) [2] & 300 & 2 \\
\hline & Patel et al. (2012) [64] & 150 & 12 \\
\hline & Getachew (2014) [27] & 206 & 24.3 \\
\hline & Kumar (2015) [45] & 150 & 2.7 \\
\hline \multirow[t]{6}{*}{ Nausea } & Javadnia et al. (2006) [38] & 68 & 29 \\
\hline & Agnihotri and Sagoo (2010) [2] & 300 & 30 \\
\hline & Mulu and Tebagu (2012) [55] & 147 & 0.7 \\
\hline & Patel et al. (2012) [64] & 150 & 22 \\
\hline & Getachew (2014) [27] & 206 & 30.1 \\
\hline & Kumar (2015) [45] & 150 & 3.3 \\
\hline \multirow[t]{2}{*}{ Vomiting } & Patel et al. (2012) [64] & 150 & 2 \\
\hline & Getachew (2014) [27] & 206 & 2.4 \\
\hline \multirow[t]{4}{*}{ Sweating } & Mulu and Tebagu (2012) [55] & 147 & 36.1 \\
\hline & Patel et al. (2012) [64] & 150 & 8 \\
\hline & Getachew (2014) [27] & 206 & 21.4 \\
\hline & Kumar (2015) [45] & 150 & 35.3 \\
\hline \multirow[t]{3}{*}{ Palpitation } & Mulu and Tebagu (2012) [55] & 147 & 5.4 \\
\hline & Patel et al. (2012) [64] & 150 & 0.7 \\
\hline & Getachew (2014) [27] & 206 & 15 \\
\hline \multirow[t]{2}{*}{ Insomnia } & Patel et al. (2012) [64] & 206 & 2 \\
\hline & Getachew (2014) [27] & 206 & 9.2 \\
\hline \multirow[t]{2}{*}{ Lack of concentration } & Javadnia et al. (2006) [38] & 68 & 38.7 \\
\hline & Agnihotri and Sagoo (2010) [2] & 300 & 40 \\
\hline \multirow[t]{2}{*}{ Restlessness } & Javadnia et al. (2006) [38] & 68 & 19 \\
\hline & Agnihotri and Sagoo (2010) [2] & 300 & 18.7 \\
\hline \multirow[t]{2}{*}{ Eye irritation } & Mulu and Tebagu (2012) [55] & 147 & 27.2 \\
\hline & Kumar (2015) [45] & 150 & 63.3 \\
\hline Headache & Kumar (2015) [45] & 150 & 10 \\
\hline \multirow[t]{2}{*}{ Desire to leave the dissecting room } & Mulu and Tebagu (2012) [55] & 147 & 10.9 \\
\hline & Kumar (2015) [45] & 150 & 9.3 \\
\hline \multirow[t]{2}{*}{ No symptoms } & Cahill and Ettarh (2009) [12] & 166 & 17.4 \\
\hline & Patel et al. (2012) [64] & 150 & 39.3 \\
\hline Overall weighted mean & & \multicolumn{2}{|c|}{15.2} \\
\hline
\end{tabular}

humanistic dimension of anatomy as illustrated by this quotation, "I am thankful for this journal because it allows me to express my thoughts and feelings about my journey since it's difficult to speak to anyone else without freaking them out". Research that provides insight into the undergraduate student experience, perceptions and outcomes of reflective-journaling, is required to validate the continued use of reflective-journaling as a way to develop reflective skills.

\section{RECOMMENDATIONS FOR FUTURE RESEARCH}

Since this was the first time that such journal writing was conducted in our Discipline at our University, 
Table 5. Physical and psychological factors emanating from cadaver interaction

\begin{tabular}{llcc}
\hline & Author (year) & Sample size (n) & Incidence (\%) \\
\hline Complaints of smell & Abu-Hijleh et al. (1997) [1] & 205 & 91 \\
& Bataineh et al. (2006) [5] & 145 & 58.5 \\
& Agnihotri and Sagoo (2010) [2] & 300 & 66.7 \\
& Dubhashi et al. (2011) [20] & 415 & 78 \\
& Mulu and Tebagu (2012) [55] & 147 & 52.4 \\
& Patel et al. (2012) [64] & 150 & 42.7 \\
Fear of infection & Getachew (2014) [27] & 206 & 60.2 \\
& Saha et al. (2015) [74] & 99 & 61.1 \\
& Abu-Hijleh et al. (1997) [1] & 205 & 62 \\
Recurring visual images of the cadaver & Bataineh et al. (2006) [5] & 145 & 50.3 \\
Negative influence on routine activities & Patel et al. (2012) [64] & 150 & 4 \\
Thoughts of leaving the course & Getachew (2014) [27] & 206 & 33.5 \\
& Abu-Hiljeh et al. (1997) [1] & 205 & 38 \\
Conflict with religious beliefs & Agnihotri and Sagoo (2010) [2] & 300 & 90 \\
Conflict with ethical/moral beliefs & Dubhashi et al. (2011) [20] & 415 & 52 \\
Curiosity or thoughts about the donor & Dubhashi et al. (2011) [20] & 415 & 5 \\
& Saha et al. (2015) [74] & 99 & 4 \\
\hline Overall weighted mean & Naz et al. (2011) [56] & 500 & 18.6
\end{tabular}

understanding undergraduate student experiences and perspectives could inform guiding principles and strategies that could serve to make reflective journaling more valuable and desirable. Some recommendation are as follows.

Even though Dedication Ceremonies are held at the beginning of the anatomy academic calendar, these pre-education sessions must be handled delicately and sensitively. Pre-education must include a professional counsellor so that students can opt for individual counselling if need be. The authors support the views expressed by Jones et al. [41] regarding implementation of memorial ceremonies for body donors in the anatomy programme. These ceremonies should be student driven to explore learners' reflections on humanity, respect, gratitude and personal growth.

Students should be advised to prepare mentally and emotionally before entering the dissecting laboratory so that they are emotionally involved and stimulated. Better preparation and debriefing for coping with dissection is required as there is some evidence to suggest that individuals can be "inoculated" against the stressful effects of handling a dead body [51]. Hafferty [31] referred to the cadaver as the "ambiguous man" to highlight its material (i.e. of being a teacher and not viewed as a mere medical object) as well as its personal qualities (name, age, cause of death). Several authors suggest that supplying as much personal and medical history of the cadaver would reinforce respect and compassion to interested students $[19,69,86,88-90]$. This may alleviate some of the stresses experienced by students. We also support the recommendations by some researchers that there is a need for the inclusion of courses on emotions and how to manage them in the anatomy curriculum [50] and concur with Nnodim [59] that a formal course on death and dying should begin at the pre-clinical level and extend into the clinical years.

We support the views expressed by Weeks et al. [89] that students should be encouraged to talk about the thoughts and feelings aroused by dissection and to reflect on these experiences. The authors propose that a commemoration ceremony be held at the end of an emotionally and intellectually demanding course to give students closure.

One limitation of this study is that we did not have detailed statistical socio-demographic data on the students to weight the results for representativeness. However, a strength of the study is the successful implementation of a research tool to document studentdissection room experiences. In future studies, we 
would like to investigate the possible role of creative journaling as a component of the course assessment.

Educators need to hold onto their ideals and continue to "teach to change the world" [21] and we support Hildebrandt's [33] recommendation that "it is the duty of anatomical educators to prepare, accompany and support students during the challenging situation of the dissection course". Perhaps developing a method where students are given more information about their cadaver, while protecting the anonymity of the donor and family would be beneficial in alleviating strong emotional student responses. Anatomy educators are correct in pursuing the teaching and learning of reflection in undergraduate education and it behoves them to utilise various tools and strategies to facilitate the growth of students into reflective practitioners. Reflective activities provide students with opportunities to think critically and can provide personal learning, transformation and betterunderstanding leading to self-actualisation. Such a student with improved personal attributes will be better positioned to provide excellent healthcare. If reflective learning is to be made a course requirement, it is important that the assessment is formative and does not distort the demonstrated benefits. Anatomists need to explain in detail the steps necessary for dissection and that dissection is performed with the respect of legislation, ethics and human rights.

\section{CONCLUSIONS}

We believe that our study offers essential information on encouraging self-reflection regarding anatomy and health care, examining the student-cadaver relationship, probing questions about spirituality and religion and exploring the emotional responses to dissection. This study also indicates that such journal writing may be a way of assisting students who experience anxiety and stress to first explore and then reduce these negative emotions. Integrating creative projects such as journal writing into anatomy courses should be encouraged as it provides a means of enhancing and enriching student awareness on issues that many students wonder about but cannot express easily.

\section{Acknowledgements}

The authors thank the allied health science and medical students who participated in this study for sharing their personal experiences. The authors are also profoundly grateful to the cadavers who donated their bodies to health education.

\section{REFERENCES}

1. Abu-Hijleh MF, Hamdi NA, Moqattash ST, et al. Attitudes and reactions of Arab medical students to the dissecting room. Clin Anat. 1997; 10(4): 272-278, doi: 10.1002/(SICI)10982353(1997)10:4<272::AID-CA10>3.0.CO;2-H, indexed in Pubmed: 9213046.

2. Agnihotri G, Sagoo MG. Reactions of first year Indian medical students to the dissection hall experience. Nat J Integ Res Med. 2010; 1(4): 4-9.

3. Amadio PC. Reaffirming the importance of dissection. Clin Anat. 1996; 9(2): 136-137, doi: 10.1002/(SICI)10982353(1996)9:2<136::AID-CA7>3.0.CO;2-F, indexed in Pubmed: 8720789.

4. Atkins S, Murphy K. Reflection: a review of the literature. J Adv Nurs. 1993; 18(8): 1188-1192, indexed in Pubmed: 8376656.

5. Bataineh ZM, Hijazi TA, Hijleh MF. Attitudes and reactions of Jordanian medical students to the dissecting room. Surg Radiol Anat. 2006; 28(4): 416-421, doi: 10.1007/s00276-0060101-4, indexed in Pubmed: 16568219.

6. Bernard E. Knowledge, Attitude and Practice of Nigerian Preclinical Students to Cadaver Dissection. IOSR J Dental Med Sci. 2012; 2(5): 33-36, doi:10.9790/0853-0253336.

7. Bertman S, Marks S. The dissection experience as a laboratory for self-discovery about death and dying: Another side of clinical anatomy. Clin Anat. 1989; 2(2): 103-113, doi: 10.1002/ ca.980020207.

8. Bob MH, Popescu CA, Suciu ŞM, et al. First year medical students' attitude toward anatomical corpse dissection and its relationship with their personality. Rom J Morphol Embryol. 2015; 56(1): 321-324, indexed in Pubmed: 25826524.

9. Bohl M, Bosch P, Hildebrandt S. Medical students' perceptions of the body donor as a. Anat Sci Educ. 2011; 4(4): 208-213, doi: 10.1002/ase.231, indexed in Pubmed: 21618447.

10. Bornman PC, Krige JEJ. Perspectives on surgery in the new South Africa. World J Surg. 2005; 29(8): 949-952, doi: 10.1007/ s00268-005-0141-7, indexed in Pubmed: 15983717.

11. Boyd E, Fales A. Reflective Learning. J Hum Psych. 2016; 23(2): 99-117, doi: 10.1177/0022167883232011.

12. Cahill KC, Ettarh RR. Attitudes to anatomy dissection in an Irish medical school. Clin Anat. 2009; 22(3): 386-391, doi: 10.1002/ ca.20777, indexed in Pubmed: 19280654.

13. Carter $C$. The use of journals to promote reflection. Action Teacher Education. 1998; 19(4): 39-42, doi: 10.1080/01626 620.1998.10462890.

14. Clark DC, Zeldow PB. Vicissitudes of depressed mood during four years of medical school. JAMA. 1988; 260(17): 2521-2528, indexed in Pubmed:3172426.

15. Coulehan J, Williams P, Landis D, et al. The first patient: Reflections and stories about the anatomy cadaver. Teach Learn Med. 1992; 7(1): 61-66, doi:10.1080/10401339509539712.

16. Crow SM, O'Donoghue D, Vannatta JB, et al. Meeting the family: promoting humanism in gross anatomy. Teach Learn Med. 2012; 24(1): 49-54, doi:10.1080/10401334.2012.641 487, indexed in Pubmed: 22250936.

17. Dart BC, Boulton Lewis GM, Brownlee JM, et al. Change in knowledge of learning and teaching through journal writing. Res Pap Edu. 1998; 13(3): 291-318, doi: 10.1080/0267152980130305.

18. Dinsmore CE, Daugherty S, Zeitz HJ. Student responses to the gross anatomy laboratory in a medical curriculum. Clin Anat. 2001; 14(3): 231-236, doi:10.1002/ca.1038, indexed in Pubmed: 11301472.

19. Druce $M$, Johnson $M$. Human dissection and attitudes of preclinical students to death and bereavement. Clin Anat. 2005; 7(1): 42-49, doi:10.1002/ca.980070108.

20. Dubhashi S, Dubhashi U, Singh A, et al. Medical students react to cadaveric dissections. Recent Res Sci Technol. 2011; 3(1): 135-138. 
21. Epp S. The value of reflective journaling in undergraduate nursing education: a literature review. Int J Nurs Stud. 2008; 45(9): 1379-1388, doi:10.1016/j.ijnurstu.2008.01.006, indexed in Pubmed: 18325522.

22. Escobar-Poni B, Poni ES. The role of gross anatomy in promoting professionalism: a neglected opportunity! Clin Anat. 2006; 19(5): 461-467, doi:10.1002/ca.20353, indexed in Pubmed: 16683242.

23. Evans EJ, Fitzgibbon GH. The dissecting room: Reactions of first year medical students. Clin Anat. 1992; 5(4): 311-320, doi: 10.1002/ca.980050408.

24. Fakude LP, Bruce JC. Journaling: a quasi-experimental study of student nurses' reflective learning ability. Curationis. 2003; 26(2): 49-55, indexed in Pubmed: 14596134.

25. Finkelstein $P$, Mathers L. Post-traumatic stress among medical students in the anatomy dissection laboratory. Clin Anat. 1990; 3(3): 219-226, doi:10.1002/ca.980030308.

26. Fitzgerald F. Curiosity. Minn Med. 1999; 82: 10-12.

27. Getachew D. Reaction of medical students to experiences in dissection room. Ethiop J Health Sci. 2014; 24(4): 337-342, indexed in Pubmed:25489198.

28. Grant A, Kinnersley P, Metcalf E, et al. Students' views of reflective learning techniques: an efficacy study at a UK medical school. Med Educ. 2006; 40(4): 379-388, doi: 10.1111/j.13652929.2006.02415.x, indexed in Pubmed: 16573675.

29. Gualdron AJ, Mendoza U, Zulima D. Colombian medical students' attitudes towards dissection during anatomy classes and their relationship with a score on the Jefferson Scale of Physician Empathy. Rev Fac Med. 2011; 59(4): 281-307.

30. Gustavson N. The effect of human dissection on first-year students and implications for the doctor-patient relationship. J Med Educ. 1988; 63(1): 62-64, indexed in Pubmed: 3336047.

31. Hafferty FW. Cadaver stories and the emotional socialization of medical students. J Health Soc Behav. 1988; 29(4): 344-356, indexed in Pubmed:3253325.

32. Hammer RR, Jones TW, Hussain FT, et al. Students as resurrectionists. A multimodal humanities project in anatomy putting ethics and professionalism in historical context. Anat Sci Educ. 2010; 3(5): 244-248, doi: 10.1002/ase.174, indexed in Pubmed: 20827724.

33. Hildebrandt $\mathrm{S}$. Thoughts on practical core elements of an ethical anatomical education. Clin Anat. 2016; 29(1): 37-45, doi: 10.1002/ca.22645, indexed in Pubmed: 26474826.

34. Horne DJ, Tiller JW, Eizenberg N, et al. Reactions of first-year medical students to their initial encounter with a cadaver in the dissecting room. Acad Med. 1990; 65(10): 645-646, indexed in Pubmed: 2261042.

35. Houwink AP, Kurup AN, Kollars JP, et al. Help of third-year medical students decreases first-year medical students' negative psychological reactions on the first day of gross anatomy dissection. Clin Anat. 2004; 17(4): 328-333, doi: 10.1002/ ca.10218, indexed in Pubmed: 15108339.

36. Ibarreta Gl, McLeod L. Thinking aloud on paper: an experience in journal writing. J Nurs Educ. 2004; 43(3): 134-137, indexed in Pubmed: 15072341.

37. Izunya AM, Oaikhena GA, Nwaopara AO. Attitudes to cadaver dissection in a Nigerian Medical School. Asian J Med Sci. 2010; 2(3): 89-94.

38. Javadnia F, Hashemitabar M, Kalantarmahdavi SR, et al. How to decrease the emotional impact of cadaver dissection in medical students. Pak J Med Sci. 2006; 22(2): 200-203.

39. Johnson JH. Importance of dissection in learning anatomy: personal dissection versus peer teaching. Clin Anat. 2002; 15(1): 38-44, doi:10.1002/ca.1090, indexed in Pubmed: 11835543.

40. Jones DG. Reassessing the importance of dissection: a critique and elaboration. Clin Anat. 1997; 10(2): 123-127, doi: 10.1002/(SICI)1098-2353(1997)10:2<123::AIDCA9>3.0.CO;2-W, indexed in Pubmed: 9058020.
41. Jones TW, Lachman N, Pawlina W. Honoring our donors: a survey of memorial ceremonies in United States anatomy programs. Anat Sci Educ. 2014; 7(3): 219-223, doi: 10.1002/ ase.1413, indexed in Pubmed: 24753299.

42. Karau PB, Wamachi A, Ndede K, et al. Perception to cadaver dissection and views on Anatomy as a subject between two pioneer cohorts in a Kenyan medical school. Anat J Afr. 2014; 3(2): 318-323.

43. Kometsi K, Louw J. Deciding on cadaveric organ donation in Black African families. Clin Transplant. 1999; 13(6): 473-478, indexed in Pubmed:10617236.

44. Kotzé SH, April V, Vorster W, et al. Perceptions of first year medical students to cadaver dissection at Stellenbosch University. Poster Presentation. 2009.

45. Kumar V. Attitude of first year indian medical students towards cadaver dissection. Int J Anat Res. 2015; 3(3): 1255-1258, doi: 10.16965/ijar.2015.196.

46. La Spina F, Sedda L, Pizzi C, et al. For the North Intaly Transplant Program. Donor families attitudes towards organ donation. Transplant Proc. 1993; 25(1): 1699-1701, indexed in Pubmed: 8442242.

47. Lachman N, Pawlina W. Integrating professionalism in early medical education: the theory and application of reflective practice in the anatomy curriculum. Clin Anat. 2006; 19(5): 456-460, doi: 10.1002/ca.20344, indexed in Pubmed: 16683241.

48. Lam WA, McCullough LB. Influence of religious and spiritual values on the willingness of Chinese-Americans to donate organs for transplantation. Clin Transplant. 2000; 14(5): 449-456, indexed in Pubmed: 11048989.

49. Lempp HK. Perceptions of dissection by students in one medical school: beyond learning about anatomy. A qualitative study. Med Educ. 2005; 39(3): 318-325, doi: 10.1111/j.13652929.2005.02095.x, indexed in Pubmed: 15733168.

50. Marks SC, Bertman SL, Penney JC. Human anatomy: a foundation for education about death and dying in medicine. Clin Anat. 1997; 10(2): 118-122, doi: 10.1002/(SICI)10982353(1997)10:2<118::AID-CA8>3.0.CO;2-R, indexed in Pubmed: 9058019.

51. McCarroll JE, Ursano RJ, Ventis WL, et al. Anticipation of handling the dead: effects of gender and experience. Br J Clin Psychol. 1993; 32 ( Pt 4): 466-468, indexed in Pubmed: 8298544.

52. McGarvey MA, Farrell T, Conroy RM, et al. Dissection: a positive experience. Clin Anat. 2001; 14(3): 227-230, doi: 10.1002/ ca.1037, indexed in Pubmed: 11301471.

53. Moore NA. To dissect or not to dissect? Anat Rec. 1998; 253(1): 8-9, indexed in Pubmed: 9556018.

54. Mukhtar Y, Mukhtar S, Chadwick SJ. Lost at sea: anatomy teaching at undergraduate and postgraduate levels. Med Educ. 2009; 43(11): 1078-1079, doi: 10.1111/j.13652923.2009.03513.x, indexed in Pubmed: 19874501.

55. Mulu A, Tegabu D. Medical students' attitudinal changes towards cadaver dissection: a longitudinal study. Ethiop J Health Sci. 2012; 22(1): 51-58, indexed in Pubmed: 23066333.

56. Naz S, Nazir G, Iram S, et al. Perceptions of cadaveric dissection in anatomy teaching. J Ayub Med Coll Abbottabad. 2011; 23(3): 145-148, indexed in Pubmed: 23272457.

57. Ndlovu PP. ubjective frameworks of meaning of kidney transplantation among African recipients. Unpublished master's thesis. University of Cape Town, Cape Town 1997.

58. Newell RL. Follow the royal road: the case for dissection. Clin Anat. 1995; 8(2): 124-127. Comment in Clin Anat 1995 8: 128-133, doi:10.1002/ca.980080207, indexed in Pubmed: 7712322 .

59. Nnodim JO. Preclinical student reactions to dissection, death, and dying. Clin Anat. 1996; 9(3): 175-182, doi: 10.1002/ (SICI) 1098-2353(1996)9:3<175::AID-CA9>3.0.CO;2-F, indexed in Pubmed: 8740480. 
60. O'Carroll RE, Whiten $S$, Jackson $D$, et al. Assessing the emotional impact of cadaver dissection on medical students. Med Educ. 2002; 36(6): 550-554, indexed in Pubmed: 12047670.

61. Older J. Anatomy: A must for teaching the next generation. Surgeon. 2004; 2(2): 79-90. Comment in Surgeon (2004); 2: 303-304. Author reply 304. Surgeon (2004); 2: 303; Author reply 303, Surgeon (2005) 3:56; Author reply 56, doi: 10.1016/ s1479-666x(04)80050-7.

62. Oyeyipo LP, Falana BA. Attitude of Preclinical Students to Cadaver Dissection in a South West Nigerian Medical School. Int J Trop Med. 2012; 7(1): 1-5, doi:10.3923/ijtmed.2012.1.5.

63. Palmer A, Burns $S$, Bulman C. (eds.) Reflective practice in nursing. Blackwell, London 1994: 1-3.

64. Patel B, Jadav J, Parmar A, et al. Attitude of medical students to cadaver dissection in Ahmedabad City. Int J Cur Res Rev. 2012; 4(22): 54-58.

65. Pawlina W. Professionalism and anatomy: How do these two terms define our role? Clin Anat. 2006; 19(5): 391-392, doi: 10.1002/ca.20329, indexed in Pubmed: 16683237.

66. Pearson M. Psychiatric treatment of 250 physicians. Psych Ann. 1982; 12(2): 194-206, doi: 10.3928/0048-5713-19820201-07.

67. Pearson WG, Hoagland TM. Measuring change in professionalism attitudes during the gross anatomy course. Anat Sci Educ. 2010; 3(1): 12-16, doi:10.1002/ase.113, indexed in Pubmed: 19847881.

68. Pellegrino ED. Educating the humanist physician. An ancient ideal reconsidered. JAMA. 1974; 227(11): 1288-1294, indexed in Pubmed: 4405977.

69. Penney JC. Reactions of medical students to dissection. J Med Educ. 1985; 60: 58-60.

70. Prakash PLV, Rai R, D'Costa S, et al. Cadavers as teachers in medical education: knowledge is the ultimate gift of body donors. Singapore Med J. 2007; 48(3): 186-189, indexed in Pubmed: 17344998.

71. Purvi M, Ksheersagar DD, Mishra D. Attitude of first year medical students towards dissection. J Cont Med A Dent. 2015; 3(1): 45-49.

72. Riley-Doucet C, Wilson S. A three-step method of self-reflection using reflective journal writing. J Adv Nurs. 1997; 25(5): 964-968, indexed in Pubmed:9147201.

73. Rizzolo $\sqcup$. Human dissection: an approach to interweaving the traditional and humanistic goals of medical education. Anat Rec. 2002; 269(6): 242-248, doi: 10.1002/ar.10188, indexed in Pubmed: 12467081.

74. Saha N, Chaudhuri S, Singh MM. Attitude of first year medical students in Dissection Hall. IOSR J Dent Med Sci. 2015; 14(5): 74-78.

75. Salmons PH. Psychiatric illness in medical students. Br J Psychiatry. 1983; 143: 505-508, indexed in Pubmed: 6640221.

76. Sándor I, Birkás E, Győrffy Z. The effects of dissection-room experiences and related coping strategies among Hungarian medical students. BMC Med Educ. 2015; 15: 73, doi: 10.1186/ s12909-015-0355-9, indexed in Pubmed: 25880170.

77. Satyapal KS. The treatment of human remains. SAJBL. 2012; 5(1): 55-60.

78. Shapiro J, Nguyen V, Mourra S, et al. The use of creative projects in a gross anatomy class. Journal for Learning through the Arts: A Research Journal on Arts Integration in Schools and Communities. 2006; 2(1): 1-32.

79. Snelling J, Sahai A, Ellis H. Attitudes of medical and dental students to dissection. Clin Anat. 2003; 16(2): 165-172, doi: 10.1002/ca.10113, indexed in Pubmed: 12589673.
80. Sobnach S, Borkum M, Millar AJW, et al. Attitudes and beliefs of South African medical students toward organ transplantation. Clin Transplant. 2012; 26(2): 192-198, doi: 10.1111/j.1399-0012.2011.01449.x, indexed in Pubmed: 21457343.

81. Sobral DT. Medical students' reflection in learning in relation to approaches to study and academic achievement. Med Teach. 2001; 23(5): 508-513, doi: 10.1080/01421590120042973, indexed in Pubmed: 12098374.

82. Somanath D, Srivastava S, Rajasekar SS. Experience in anatomy Lab. An analysis in preclinical students. J Healthcare Biomed Res. 2015; 2: 117-121.

83. Strauss A, Corbin J. Grounded Theory Methodology. In: Denzin NK, Lincoln YS (eds.). Handbook of qualitative research. Sage Publications, Thousand Oaks 1994: 217-285.

84. Swartz WJ. Using gross anatomy to teach and assess professionalism in the first year of medical school. Clin Anat. 2006; 19(5): 437-441, doi:10.1002/ca.20331, indexed in Pubmed: 16683238.

85. Tryssenaar J. Interactive journals: an educational strategy to promote reflection. Am J Occup Ther. 1995; 49(7): 695-702, indexed in Pubmed:7573341.

86. Wagoner NE, Romero-O'Connell JM. Privileged learning. Anat Sci Educ. 2009; 2(1): 47-48, doi: 10.1002/ase.65, indexed in Pubmed: 19217069.

87. Walker SE. Journal writing as a teaching technique to promote reflection. J Athl Train. 2006; 41(2): 216-221, indexed in Pubmed: 16791310.

88. Wear D. Cadaver talk: Medical students' accounts of their year-long experience. Death Studies. 1989; 13(4): 379-391, doi:10.1080/07481188908252316.

89. Weeks SE, Harris EE, Kinzey WG. Human gross anatomy: a crucial time to encourage respect and compassion in students. Clin Anat. 1995; 8(1): 69-79, doi: 10.1002/ca.980080113, indexed in Pubmed: 7697517.

90. Wenger DCK. Its not your parents anatomy course. Acad Phys Scientist. 2006: 1-3.

91. Williams R, Wessel J, Gemus M, et al. Journal writing to promote reflection by physical therapy students during clinical placements. Phys Theory Prac. 2009; 18(1): 5-15, doi: 10.10 80/095939802753570657.

92. Williams RM, Wessel J. Reflective journal writing to obtain student feedback about their learning during the study of chronic musculoskeletal conditions. J Allied Health. 2004; 33(1): 17-23, indexed in Pubmed: 15053216.

93. Williams AD, Greenwald EE, Soricelli RL, et al. Medical students' reactions to anatomic dissection and the phenomenon of cadaver naming. Anat Sci Educ. 2014; 7(3): 169-180, doi: 10.1002/ase.1391, indexed in Pubmed: 23913911.

94. Winkelmann A, Güldner FH. Cadavers as teachers: the dissecting room experience in Thailand. BMJ. 2004; 329(7480): 1455-1457, doi:10.1136/bmj.329.7480.1455, indexed in Pubmed: 15604182

95. Wong FK, Kember D, Chung LY, et al. Assessing the level of student reflection from reflective journals. J Adv Nurs. 1995; 22(1): 48-57, indexed in Pubmed: 7560535.

96. Woodward H. Reflective Journals and Portfolios: learning through assessment. Assess Eval Higher Educ. 2006; 23(4): 415-423, doi:10.1080/0260293980230408.

97. Yeager VL. Learning gross anatomy: dissection and prosection. Clin Anat. 1996; 9(1): 57-59, doi: 10.1002/(SICI)10982353(1996)9:1<57::AID-CA12>3.0.CO;2-9, indexed in Pubmed: 8838283 